\title{
Antarctic Paleobiology: Glacial refugia and constraints on past ice-sheet reconstructions
}

Louise Newman' ${ }^{1}$, P. Convey ${ }^{2}$, J.A.E. Gibson ${ }^{3}$ and K. Linse ${ }^{2}$

1PAGES International Project Office, Bern, Switzerland; newman@pages.unibe.ch

${ }^{2}$ British Antarctic Survey, Cambridge, UK; ${ }^{3}$ Tasmanian Aquaculture and Fisheries Institute, University of Tasmania, Hobart, Australia

\section{Paleobiological approaches reveal the long-term (Myr) survival of Antarctic terrestrial, marine and freshwater fauna in glacial refugia, which provides constraints for models of past ice sheet extent.}

\section{Antarctic biota and glacial history - inextricably linked}

Given the extremes of Antarctica today, it is difficult to imagine that ca. 500 Myr ago it was ecologically similar to contemporary temperate and subtropical latitudes. With complete isolation of the continent by ca. 45-30 Myr, followed by continental cooling and widespread glaciation (Lear et al., 2000; Zachos, et al., 2001; Miller et al., 2005), the terrestrial biota were reduced to a tundra-like community analogous to that of modern southernmost S. America, before largely being driven to extinction due to the development of hyperarid, polar-desert conditions at 14 Myr ago (Lewis et al., 2008). Molecular studies of the modern micro-invertebrate biota indicate that remaining communities became fragmented (e.g., Stevens et al., 2006) and distinct, with apparently little successful immigration from northerly landmasses.
Today's terrestrial and freshwater fauna are restricted to the ca. $0.3 \%$ of ice-free land currently found on the coast and on inland, higher-altitude mountain ranges (nunataks). They are dominated by small ( $200 \mu \mathrm{m}-5 \mathrm{~mm})$ and inconspicuous invertebrates and are usually associated with simple vegetation (lichens, mosses, algae). Within the scope of their coarse spatial resolution, model reconstructions of past ice-sheet extent suggest that most of the presently ice-free regions would have been completely ice covered during previous glacial maxima (Huybrechts, 2002; DeConto and Pollard, 2003). This notion has historically placed large constraints on our understanding of the antiquity of the Antarctic fauna, implicitly inferring recolonization of the continent after each glacial maximum. However, recent studies of Antarctic terrestrial and freshwater biota indicate ancient origins for many of them, suggesting survival in isolation for up to tens of millions of years (Fig. 1; Bayly et al., 2003; Cromer et al., 2006; Convey and Stevens, 2007; Gibson and Bayly, 2007; Convey et al., 2008).

\section{Terrestrial evidence}

On land, several lines of evidence point to this conclusion and, indeed, to a more complex picture of intra-Antarctic biological isolation and species radiation over considerable timescales. Recent biogeographical studies identify striking levels of species endemism within the current invertebrate fauna and lichen flora, both at continental and regional scale (Maslen and Convey, 2006; Convey et al., 2008; Pugh and Convey, 2008) - the latter also highlighting that the continent cannot be treated as a single entity when considering biological refugia; each region has its own distinct history. The strength of the

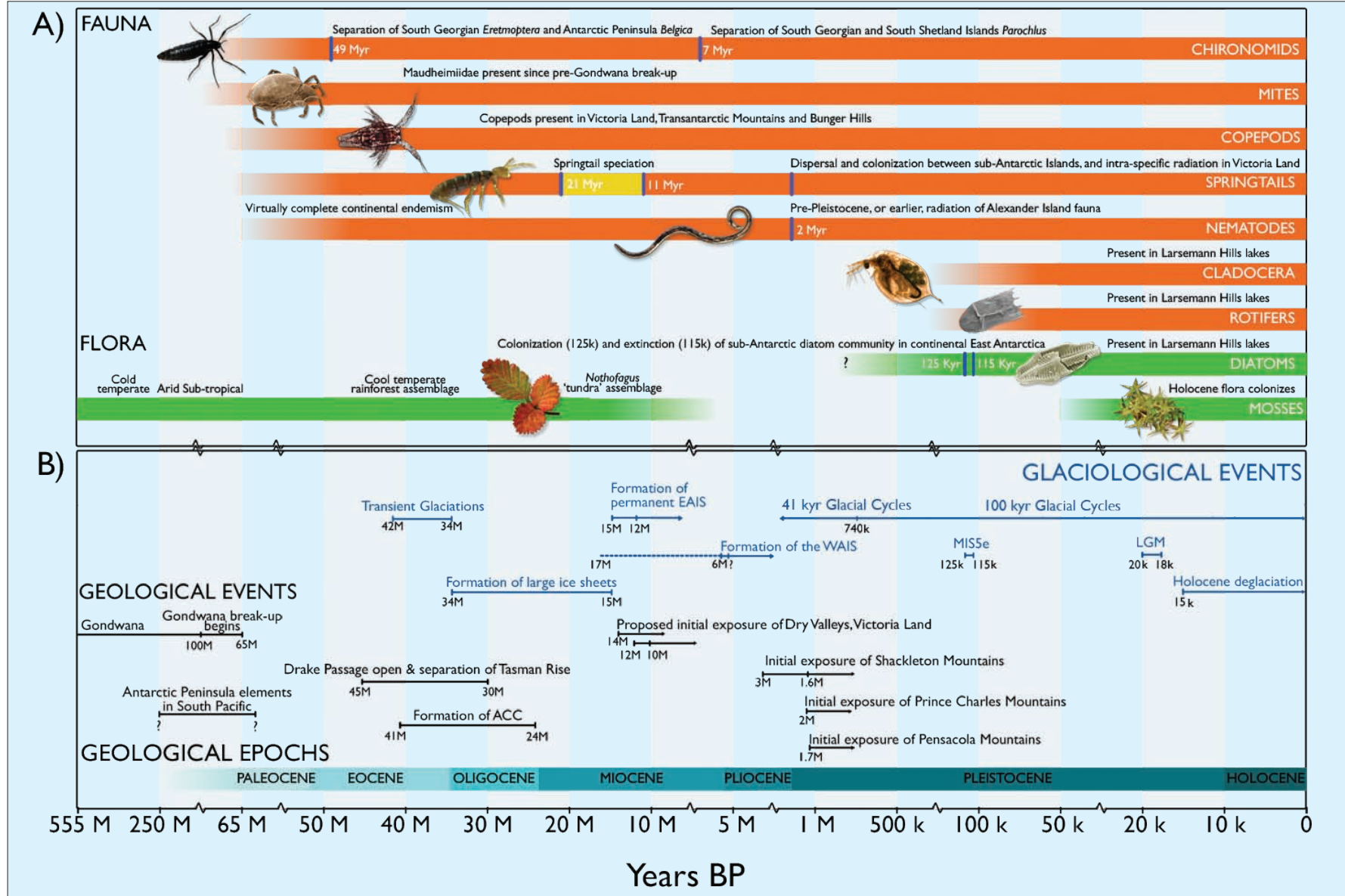

Figure 1: Molecular, phylogenetic and fossil evidence for the timing of biological colonizations and extinctions in Antarctica since the break-up of Gondwana. $\boldsymbol{A}$ ) Schematic timelines for the survival of different flora and fauna on the continent; $\boldsymbol{B}$ ) Key geological and glaciological episodes in the evolution of Antarctica that will have influenced flora and fauna. WAIS = West Antarctic Ice Sheet, EAIS = East Antarctic Ice Sheet, ACC = Antarctic Circumpolar Current, LGM = Last Glacial Maximum. Note that the geological timescale is non-linear and that most microorganisms are excluded from this schematic diagram. Modified from Convey et al. (2008). 


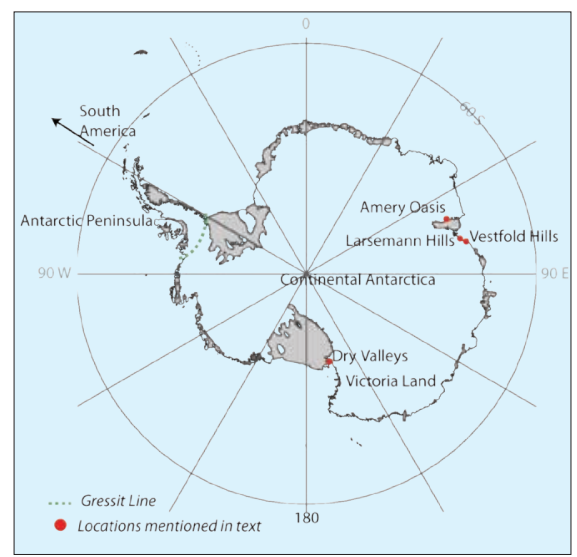

Figure 2: Map of Antarctica showing the location of places mentioned in the text.

boundary between faunal communities of the Antarctic Peninsula and continental Antarctica, across which no species are shared in many of the groups present, has led to the naming of the "Gressitt Line" (Fig. 2), a biogeographical boundary of similar significance to the Wallace Line of SE Asia (Chown and Convey, 2007). Moreover, molecular biological approaches, including phylogeography and estimations based on molecular clocks, have provided strong evidence of ancient colonization and divergence events on timescales of millions to tens of millions of years (e.g., Allegrucci et al., 2006; Stevens et al., 2006; Jansen van Vuuren et al., 2007).

\section{Lacustrine evidence}

Analogous evidence of an ancient fauna is available from Antarctic freshwater lakes. An essential requirement for the long-term survival of freshwater fauna on the continent is the continued existence of lakes. If ice-free areas were limited during glacial maxima, rock-based lakes were likely far scarcer. However, ice-based systems occur that can harbor a diverse fauna (Vincent et al., 2000; Christner et al., 2003). Due to this necessity for habitat persistence, direct evidence provided by lakes is generally on a shorter timescale (i.e., Pleistocene) than for terrestrial studies, although indirect approaches (i.e., biogeographical) suggest longer-term survival for some species. For example, the copepod Gladioferens antarcticus has a distribution suggesting an ancient association with Antarctica (Bayly et al., 2003). This species, which is a member of a genus that otherwise occurs along the south coast of Australia and New Zealand, is the most primitive of its sub-genus, and therefore cannot have been derived recently from other species. It is concluded that it has been associated with the Antarctic continent since the separation of Antarctica and Australia some 30 Myr ago (Bayly et al., 2003).
More direct evidence for long-term survival of fauna (over shorter but still preLast Glacial Maximum (LGM) timescales) comes from the study of faunal remains in lake sediments. Some lakes, notably Lake Reid (Larsemann Hills), have existed since MIS 5 (i.e., were not overrun and scoured by ice during the LGM). Faunal remains in Lake Reid sediments indicate that the cladoceran Daphniopsis studeri and the rotifer Notholca sp. have occurred in the lake throughout its existence (Cromer et al., 2006). Sediment cores from younger lakes also support the continued existence of animal populations on the continent. In most cases, the species currently present in a lake arrived soon after its formation, suggesting a local source (Cromer et al., 2005, 2006; Gibson and Zale, 2006). Furthermore, diversity has not increased markedly over time, which is inconsistent with continual colonization from extracontinental sources.

\section{Marine evidence}

In the marine realm, the historical view that the Antarctic shelf fauna was wiped out during glacial maxima and recolonized after ice-sheet retreat is currently changing. Clarke and Crame (1992) defined the term "Antarctic diversity pump" for the process that caused speciation events (development of a new species) in marine taxa, initiated by repeated glacial and interglacial cycles. Molecular phylogenetic studies on several marine groups have revealed successful radiation events (increases in diversity or morphological varaibility due to adaptation to environmental change) in several taxa since the onset of the Antarctic Circumpolar Current (ACC) 30 Myr ago, e.g., amphipods (Lörz and Held, 2004), isopods (Held, 2000; Raupach et al., 2007; Brökeland and Raupach, 2008) and octopods (Allcock and Piertney, 2002). Studies on the bivalve Limatula in the Southern Ocean have shown that species of this genus were able to cross the ACC (Page and Linse, 2002).

Dayton and Oliver's (1977) idea of refugia on the Antarctic shelf, which enable species with good dispersal abilities to recolonize the shelf after glaciation events or move between refugia during events (Thatje et al., 2005), is being tested with molecular population genetics. First results from recent studies on the crinoid Promachocrinus kerguelensis (Wilson et al., 2007) show that radiation events occurred after the onset of the ACC but before the LGM, suggesting that $P$. kerguelensis survived the LGM on the Antarctic shelf. As many Antarctic marine species have wide water-depth distribution levels, often ranging from the shelf to the continental slope, more studies specifically on species with restricted shelf-depth range are needed to confirm the existence of shelf refugia and, hence, whether this raises analogous questions in the marine environment to those outlined for land; e.g., are there ancient components of the current marine fauna of Antarctica that survived glaciations in refugia?

\section{Conclusions}

The general conclusion from these studies is that for different evolutionary lines to have remained in Antarctica over these timescales, the Antarctic shelf must have been at least partially free of grounded ice, and there must have been seasonally ice-free habitats available on land. For some biotas, such as those of the Victoria Land Dry Valleys and certain inland mountain ranges, this does not challenge current understanding of previous ice extent and thickness, as these regions are known to have maintained ice-free areas during more recent glacial maxima. However, no such explanation currently exists for other elements of the Antarctic biota that occupy low altitude and often coastal habitats today, with no possibility of nunatak or higher altitude refugia for survival through glacial maxima. It must be concluded that many of the coastal icefree areas present today were at least partially ice-free throughout repeated glacial maxima, which puts a significant restraint on the extent of the Antarctic ice sheet during these times. A different model of glaciation has to be developed, possibly involving the formation of ice shelves associated with major outlet glaciers but limited expansion elsewhere. This conclusion is consistent with the marine data, which support asymmetrical circumAntarctic expansion of the ice sheet.

In summary, numerous paleobiological approaches now indicate greater antiquity in the Antarctic terrestrial, marine and freshwater biota than previously thought. Moreover, ancient biogeographical boundaries are still evident in modern species distribution. The survival of ancient components of the Antarctic biota has significance beyond the purely biological realm, by providing a novel biological constraint on past ice sheet extent and thickness. The biological evidence indicates that model reconstructions currently overestimate past ice coverage. 


\section{Note}

Distributional data for the terrestrial and aquatic fauna is available via the Evolution and Biodiveristy in the Antarctic (EBA) dataportal (www. eba.aq/), while marine data is available in the SCAR Marine Biodiversity Information Network (SCAR-MarBIN) database (www.scarmarbin. be/).

\section{References}

Convey, P. and Stevens, M.I., 2007: Antarctic biodiversity, Science, 317 1877-1878.

Convey, P., Gibson, J.A. Hellenbrand, C, Hodgson, D. A, Pugh, PJ.A. Smellie, J.L. and Stevens, M.I., 2008: Antarctic terrestrial life challenging the history of the frozen continent? Biological Reviews, 83: 103-117.

Cromer, L., Gibson, J.A.E., Swadling, K.M. and Hodgson, D., 2006: Evidence for a lacustrine faunal refuge in the Larsemann Hills, East Antarctica, during the Last Glacial Maximum, Journal of Biogeography, 33: 1314-1323
Gibson, J.A.E. and Bayly, I.A.E., 2007: New insights into the origins of crustaceans of Antarctic lakes, Antarctic Science, 19: 157-164.

Page, T. and Linse, K., 2002: More evidence of speciation and dispersal across the Antarctic Polar Front through molecular systematics of Southern Ocean Limatula (Bivalvia: Limidae), Polar Biology, 25: $818-826$.

For full references please consult:

www.pages-igbp.org/products/newsletters/ref2009_1.html

\section{Sea-ice proxies in Antarctic ice cores}

Regine Röthlisberger and Nerilie Abram

British Antarctic Survey, Cambridge, UK; rro@bas.ac.uk

\section{Chemical parameters routinely analyzed in ice cores hold information on past changes in sea ice extent around Antarctica, providing a long-term perspective on sea ice.}

Sea ice plays a crucial role in the Earth System: Apart from its direct influence on radiative balance via its albedo, it also has a large influence on ocean-atmosphere exchange processes, ocean stratification and atmospheric circulation. Furthermore, sea ice is instrumental in the formation of deepwater masses and thus influences the global thermohaline circulation. Despite its importance, sea ice remains a poorly constrained component in model simulations of past and ongoing climate change. Much of this uncertainty is due to the paucity of information about past sea ice conditions.

Various methods have been applied to derive past sea ice extent. For the most

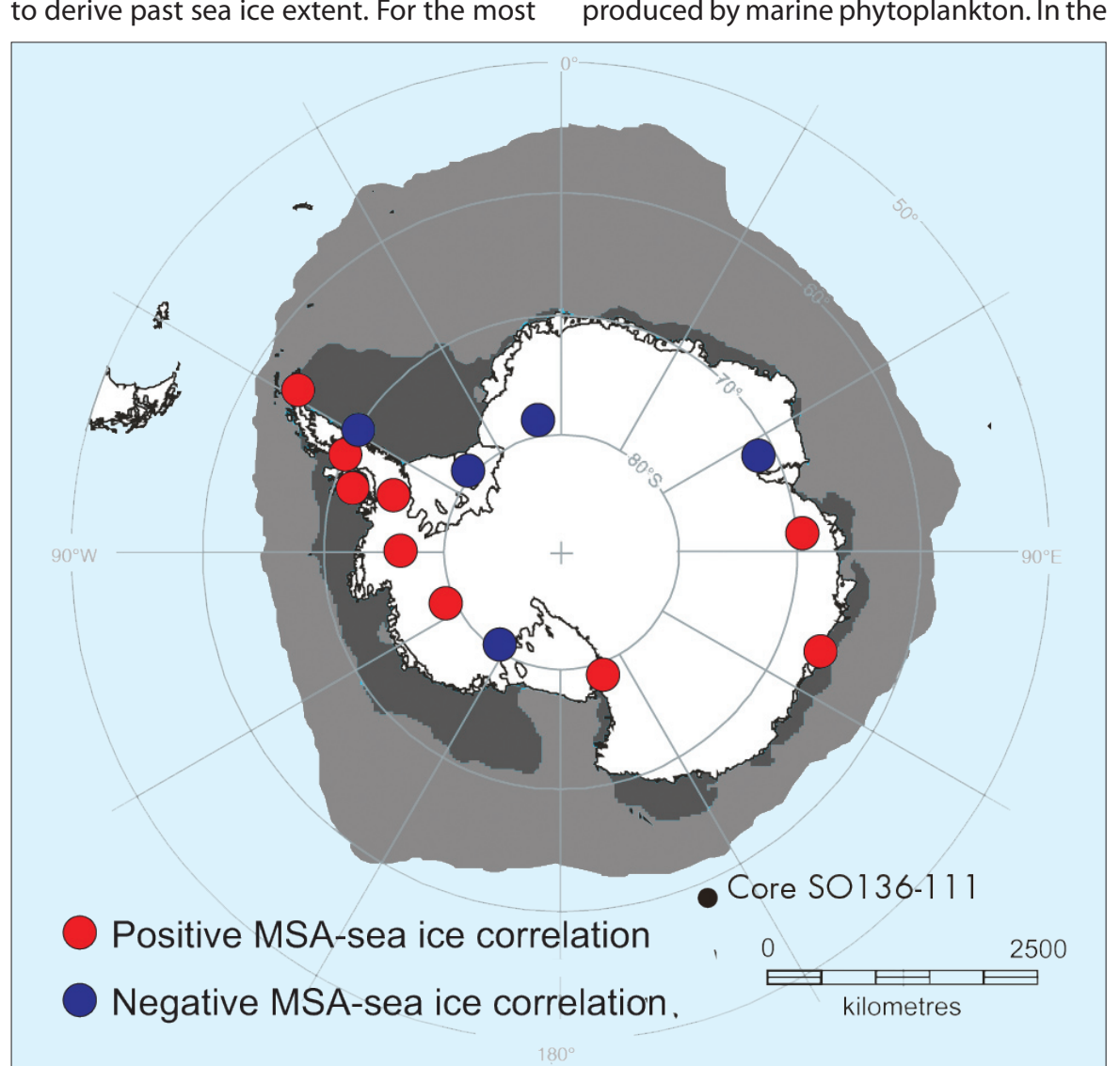

Figure 1: Spatial pattern of the correlation between methanesulfonic acid (MSA) for different coastal Antarctic ice core sites, and the winter maximum sea ice extent for the longitudinal sector considered to be the relevant source (Welch et al., 1993; Sun et al., 2002; Curran et al., 2003; Foster et al., 2006; Abram et al., 2007; Abram, unpublished data). Light and dark gray shading denotes mean winter and summer sea ice extent, respectively.
Southern Ocean, large amounts of DMS are produced by algae in the sea-ice zone (Curran and Jones, 2000). More extensive winter sea ice promotes increased phytoplankton activity during seasonal sea ice melt, and the associated increased release of DMS is reflected by greater amounts of MSA deposited in nearby snow layers.

A pioneering paper by Curran et al. (2003) showed remarkable agreement between the MSA record from Law Dome, a coastal ice dome in East Antarctica, and the satellite-derived sea ice maximum. The MSA record clearly traced the decadal-scale variability found in the satellite record of maximum sea ice extent. Using MSA as a proxy for regional sea ice extent allowed the satellite record to be put into a century-scale context, from which Curran et al. (2003) inferred a $20 \%$ decline in sea ice since 1950 for the $80-140^{\circ} \mathrm{E}$ sector.

Ice core MSA records from a number of other coastal sites also show a positive relationship between MSA and winter sea ice extent (Welch et al., 1993; Foster et al., 2006; Abram, unpublished data), making this a promising proxy for reconstructing regional patterns of sea ice change around Antarctica (Fig. 1). However, there are some limitations in using MSA as a sea ice proxy. Recent work in the Weddell Sea region has found that in some locations the MSA signal in ice cores is more strongly influenced by atmospheric transport strength and direction (Fundel et al., 2006; Abram et al., 2007). There is also evidence that the MSA sea ice proxy is not reliable at some sites around the Ross Sea and Lambert Glacier (Sun et al., 2002), suggesting that embayed coastal locations may not be suitable for sea ice reconstructions, due to geographical constraints on wind-driven transport. Work is currently underway to develop additional MSA records from near-coastal ice core sites, to help define the characteristics of sites where this proxy is reliable, in order to build a regional-scale 